\title{
Caracterização química e tecnológica das folhas, caules e planta inteira da Ipomoea pes-caprae (L.) R. Br., Convolvulaceae, como matéria-prima farmacêutica
}

\author{
Samyra T. Barni, Valdir Cechinel Filho, Angélica G. Couto*
}

\author{
Núcleo de Investigações Químico-Farmacêuticas, Universidade do Vale do Itajaí. Rua Uruguai, 458, \\ Bloco 17, 88302-202 Itajaí-SC, Brasil.
}

\begin{abstract}
RESUMO: Ipomoea pes-caprae (L.) R. Br., (Convolvulaceae), planta que ocorre abundantemente nas dunas do litoral é popularmente conhecida como "salsa-da-praia", e usada na medicina popular devido às suas propriedades analgésica, antiinflamatória e cicatrizante. A partir das partes aéreas frescas foram desenvolvidos protocolos para o seu tratamento prévio e controle de qualidade, com o propósito de caracterizar a planta como matéria-prima farmacêutica. A perda por secagem mostrou que as folhas apresentam menor rendimento de matéria seca em relação aos caules, devido ao seu maior teor de água. A secagem e moagem teve por objetivo a manutenção da perda por dessecação abaixo do valor máximo permitido para drogas vegetais. As folhas e caules secos e moídos foram classificados como pós grossos através da análise granulométrica por tamisação, e caracterizados segundo testes farmacopeicos para drogas vegetais. A determinação de cinzas indicou a presença de material inorgânico, possivelmente areia, associado ao habitat da espécie. O teor de extrativos solúveis em água foi maior nas folhas, seguido dos caules e proporcional na planta inteira, correlacionando-se ao teor de flavonoides totais. A cromatografia em camada delgada das soluções extrativas hidroetanólicas mostrou diferenças apenas com relação à intensidade das manchas, e indicação da presença de isoquercitrina, sendo mais evidente nas folhas.
\end{abstract}

Unitermos: controle de qualidade, matéria-prima vegetal, Ipomoea pes-caprae, flavonoides totais.

\begin{abstract}
Chemical and technological characterization of Ipomoea pes-caprae (L.) R. Br., Convolvulaceae, leaves, branches and entire plant as a pharmaceutical raw material". Ipomoea pes caprae (L.) R. Br., (Convolvulaceae), a pantropical stand plant, popularly known as "salsa-da-praia", is used in folk medicine because of its analgesic, antinflammatory and healing properties. Protocols were developed from the fresh aerial plants to establish their previous treatment and quality control in order to get it characterized as a pharmaceutical raw material. The loss of water on drying in an air oven, showed that leaves represent a lesser dried mass yield than branches, as a result of its higher water content. Drying and milling were aimed at keeping the loss on drying below the limit value accepted for herbs. Dried and milled leaves and branches were classified as thick powder through the sieving method, before they were characterized according to pharmacopoeial tests for herbs. The determination of ashes indicated the presence of inorganic materials, most probably due to sand content which came from the herb habitat. The soluble water extractives were greater from the leaves, followed by the branches and proportional for the entire plant. These results showed to be correlated to the total flavonoid content. The thin layer chromatography for the hydroethanolic solutions only demonstrated differences related to the spots color intensity, and indicated the presence of isoquercitrin, being more evident from the leaves.
\end{abstract}

Keywords: quality control; herbal raw material; Ipomoea pes-caprae; total flavonoid content.

\section{INTRODUÇÃO}

A riqueza de recursos naturais, da qual o Brasil se privilegia, oferece uma gama inesgotável de espécies vegetais com potencial na profilaxia e tratamento de várias enfermidades. A transformação desse potencial em benefícios para a saúde humana requer investimentos nas diversas áreas de pesquisa e desenvolvimento, sendo, portanto, alvo de esforços multidisciplinares (Sonaglio et al., 2003; Calixto, 2005; Cragg \& Newman, 2007).

A definição de critérios de qualidade para insumos farmacêuticos de origem vegetal é de suma importância para garantir a manutenção da eficácia do produto final, especialmente devido à complexidade de composição 
destas matérias-primas e às variações ligadas às condições de cultivo e coleta do vegetal, assim como de tratamentos empregados para promover sua estabilidade (Sonaglio et al., 2003).

Ipomoea pes-caprae (L.) R. Br., Convolvulaceae, é uma planta de restinga, conhecida popularmente como salsa-da-praia, encontrada extensivamente sobre as dunas das praias em toda região litorânea brasileira, tradicionalmente usada na medicina popular como tônica e purgativa. A decocção das raízes e folhas dessa planta também tem sido utilizada no tratamento do reumatismo, gota e gonorréia. Externamente, a pasta das folhas é aplicada para o tratamento de queimaduras, especialmente causadas pelo veneno de água-viva (Wasuwat, 1970). Além disso, foi demonstrado que o extrato metanólico da planta exibe efeito espasmolítico em preparações de músculo liso (Emendorfer et al., 2005), confirmando os resultados obtido anteriormente (Pongprayoon et al., 1989, 1991a, b, 1992). Estudos pré-clínicos em camundongos (Krogh et al., 1999; De Souza et al., 2000) validaram as propriedades analgésicas da planta, confirmando que os flavonóides e terpenos são os principais princípios ativos.

A legislação vigente, para autorização de produção e comercialização de produtos fitoterápicos (Brasil, 2004), exige a documentação de todas as ações direta ou indiretamente relacionadas à sua produção. Para tanto, a existência de especificações oficiais de matériasprimas farmacêuticas, oriundas de plantas medicinais, representa um passo importante para o estabelecimento de critérios mínimos para aceitação da qualidade.

A abundante ocorrência natural, o uso frequente na medicina popular, a confirmação do potencial terapêutico em estudos pré-clínicos e o conhecimento fitoquímico para esta espécie vegetal, estimulam o estudo tecnológico da I. pes-caprae como matéria-prima farmacêutica. $\mathrm{O}$ presente estudo pretende contribuir para o controle de qualidade desta espécie a partir do conhecimento das suas características físicas, químicas e de interesse ao desenvolvimento tecnológico de fitoterápicos.

\section{MATERIAIS E MÉTODOS}

\section{Material vegetal}

A planta foi coletada na praia de Esplanada, município de Jaguaruna-SC, em fevereiro de 2006. Uma exsicata do vegetal foi depositada no Herbário Barbosa Rodrigues (Itajaí-SC) sob o registro V C Filho 009.

\section{Tratamento prévio do material vegetal}

Após a coleta foi realizada a triagem através da separação manual das folhas, caules, botões e flores, com vistas à eliminação de material estranho e secagem individual das diferentes partes vegetais. Cada parte foi disposta separadamente em bandejas na estufa com circulação de ar à temperatura de $35^{\circ} \mathrm{C}$ durante 11 dias. Após a secagem, cada parte seca foi moída em moinho de martelos, com abertura de saída de $3 \mathrm{~mm}$.

\section{Determinação da perda por secagem e rendimento de matéria seca}

Após a triagem, as folhas, caules, botões e flores frescos foram pesados. A perda por secagem foi calculada após o tratamento de secagem em estufa, expressando-se o resultado em porcentagem $(\%, \mathrm{~m} / \mathrm{m})$ de matéria seca para cada parte da planta.

\section{Matérias-primas vegetais}

Foram empregadas como matérias-primas vegetais as folhas, caules e planta reconstituída a partir das proporções das partes que representam a planta inteira, após a triagem, secagem, moagem e mistura, no caso da planta inteira.

\section{Determinação da perda por dessecação das matérias- primas vegetais}

Cerca de $0,5 \mathrm{~g}$ foram transferidos para cadinho de porcelana, previamente tarado, e levado a estufa a 105 ${ }^{\circ} \mathrm{C}$. Após duas horas, foram transferidos para dessecador, provido de sílica, e pesados imediatamente após $20 \mathrm{~min}$. A secagem e o resfriamento foram repetidos em ciclos de $1 \mathrm{~h}$ até peso constante. Os resultados expressam a média de três determinações para cada matéria-prima vegetal (F. Bras. IV, 1988).

\section{Análise granulométrica por tamisação}

Cerca de $70 \mathrm{~g}$ das folhas e caules secos e moídos foram submetidos à passagem por tamises, previamente tarados, com aberturas de malha de $2 \mathrm{~mm}, 1 \mathrm{~mm}, 0,6$ $\mathrm{mm}, 0,5 \mathrm{~mm}, 0,3 \mathrm{~mm}$ e $0,125 \mathrm{~mm}$, à sessenta vibrações por segundo, durante $20 \mathrm{~min}$ com três repetições para cada amostra. Para a análise dos dados foram calculados o tamanho médio das partículas pelo método aritmético, conforme a Equação 1, e construído o histograma de freqüência para a análise da distribuição granulométrica.

$$
d_{\text {médio }}=\frac{\sum(A M . F r \%)}{100 \%}
$$

Onde: $d_{\text {médio }}=$ diâmetro médio aritmético $(\mathrm{mm}) ; A M=$ abertura média de malha $(\mathrm{mm})$ e a $F r \%=$ fração retida percentual em cada tamis (Allen et al., 2007).

\section{Determinação de cinzas totais, insolúveis em ácido clorídrico e sulfatadas}

As análises foram realizadas em série de três 
repetições, a partir de cerca de $1,5 \mathrm{~g}$, de cada matériaprima vegetal (F. Bras .IV, 1988).

Caracterização química qualitativa por cromatografia em camada delgada

Cerca de $1 \mathrm{~g}$ das amostras, juntamente com 20 $\mathrm{mL}$ de álcool $70^{\circ} \mathrm{GL}$ foram submetidos ao refluxo por 20 min, prensados através do tecido Sontara ${ }^{\circledR}$ e filtrados sobre papel de filtro, para preparação das soluções-amostra das matérias-primas vegetais. As amostras foram aplicadas no volume de $20 \mu \mathrm{L}$ em cromatofolhas de sílica gel $\mathrm{GF}_{254}$, empregando-se como sistema eluente: ácido fórmico:ácido acético:água:acetato de etila (11:11:27:100 v/v)(F. Bras. IV, 2001). Como substâncias de referência foram empregadas soluções etanólicas de quercetina e isoquercitrina. Como sistema revelador, foi utilizada solução metanólica de difenilboriloxi-etilamina a $1 \%(\mathrm{~m} / \mathrm{v})$ e como fixador, a solução etanólica de polietilenoglicol 4000 a 0,5\% (m/v).

\section{Teor de extrativos solúveis em água}

Cerca de $1 \mathrm{~g}$ da matéria-prima vegetal seca e moída foi adicionado de $100 \mathrm{~g}$ de água, e levados a ebulição durante $10 \mathrm{~min}$. Após resfriamento, foi adicionada água até recompor o peso inicial. A seguir o extrato foi prensado através de tecido Sontara ${ }^{\circledR}$ e filtrado sobre papel de filtro. Cerca de $20 \mathrm{~g}$ do filtrado foram transferidos para cadinhos de porcelana, previamente tarados, evaporados em chapa quente a $250{ }^{\circ} \mathrm{C}$, até secura, e levados à estufa a $105^{\circ} \mathrm{C}$. Após $2 \mathrm{~h}$ foram transferidos para dessecador, e pesados imediatamente após $20 \mathrm{~min}$. A dessecação e resfriamento foram repetidos em ciclos de $1 \mathrm{~h}$ até peso constante. Foram realizados quatro ensaios para cada matéria-prima vegetal, com três repetições cada. Para o cálculo do TE foi empregada a Equação 2.

$$
T E=\frac{\mathrm{g} \cdot F D}{m-\left(m \cdot \frac{p p d)}{100}\right.} \cdot 100
$$

Onde: $T E=$ teor de extrativos solúveis em água $(\%, \mathrm{~m} / \mathrm{m})$; $\mathrm{g}=$ resíduo seco $(\mathrm{g}) ; F D=$ fator de diluição $(5) ; m=$ planta seca e moída $(\mathrm{g}) ; p p d=$ perda por dessecação da planta seca e moída (Bundesvereinigung, 1986).

\section{Análise espectrofotométrica para quantificação do teor de flavonoides totais}

Foi realizada a quantificação de flavonoides a partir de 0,4 g da matéria-prima vegetal seca e moída, seguindo a descrição na F. Bras. IV (2001). Os resultados representam a média de quatro repetições.

\section{RESULTADOS E DISCUSSÃO}

Para o conhecimento do rendimento de matéria fresca e seca, foi calculada a perda por secagem de cada parte do material vegetal. Conforme demonstram os resultados da Tabela 1 , as folhas representam a parte vegetal onde o teor de água é mais abundante, o que faz com que seu rendimento em matéria seca seja inferior aos caules.

Tabela 1. Relação de massa fresca e seca das diferentes partes da Ipomoea pes-caprae.

\begin{tabular}{|c|c|c|c|c|c|}
\hline \multirow{2}{*}{$\begin{array}{l}\text { Partes } \\
\text { vegetais }\end{array}$} & \multicolumn{2}{|c|}{ Planta fresca } & \multicolumn{2}{|c|}{ Planta seca } & \multirow{2}{*}{$\begin{array}{c}\text { Perda por } \\
\text { secagem } \\
(\%)\end{array}$} \\
\hline & massa $(\mathrm{g})$ & $(\%)$ & massa (g) & $(\%)$ & \\
\hline folhas & 1544 & 48,83 & 213 & 32,24 & 86,20 \\
\hline $\begin{array}{l}\text { flores, frutos } \\
\text { e sementes }\end{array}$ & 465 & 14,71 & 102,5 & 15,46 & 77,95 \\
\hline caules & 1153 & 36,46 & 345,18 & 52,24 & 70,06 \\
\hline Total & 3162 & 100 & 660,68 & 100 & 79,11 \\
\hline
\end{tabular}

Após as operações preliminares, como a triagem, secagem e moagem, foram caracterizadas as diferentes partes da planta, como caule, folha e a planta inteira. Especialmente para a planta inteira, foi realizada reconstituição, por meio de mistura das porcentagens de cada parte da planta seca (Tabela 1).

Os resultados da perda por dessecação das matérias-primas vegetais estão descritos na Tabela 2. O teor de umidade em matérias-primas vegetais permite a ação de enzimas, podendo acarretar a degradação de constituintes químicos (Farias, 2003). O teor máximo de umidade estabelecido varia de $8-14 \%$, (F. Bras. IV, 1988). Portanto, as operações preliminares empregadas nas folhas, caules e a planta reconstituída foram efetivos quanto à normalização do teor de umidade aos valores estabelecidos.

Tabela 2. Perda por dessecação das partes vegetais secas e moídas da Ipomoea pes-caprae.

\begin{tabular}{cccc}
\hline Parte planta & Média $(\mathrm{g})$ & Desvio padrão & DPR \% \\
\hline Folha & 8,017 & 0,025 & 0,468 \\
Caule & 10,456 & 1,625 & 15,54 \\
Inteira & 10,154 & 0,016 & 0,157 \\
\hline
\end{tabular}

DPR \% = desvio padrão relativo percentual.

Conforme o cálculo do tamanho médio das partículas, os pós das folhas $(983,57 \pm 9,10 \mu \mathrm{m}$, DPR $=0,93 \%)$ e caules $(732,95 \pm 4,65 \mu \mathrm{m}, \mathrm{DPR}=0,63 \%) \mathrm{da}$ I. pes-caprae, foram classificados como grossos $(1,70$ $\mathrm{mm} / 355 \mu \mathrm{m}$ ) segundo a descrição da F. Bras. IV (1988). No entanto, as folhas apresentaram granulometria média 
superior aos caules. Esta diferença pode ser atribuída aos fatores operacionais ligados ao tipo de moinho e às características originais da amostra. Como os caules secos da I. pes-caprae apresentam-se mais grossos e rígidos, enquanto as folhas, mais finas e macias, é provável que a eficiência quanto ao grau de redução do tamanho de partícula no processo de moagem seja mediado por mecanismos diferentes, podendo a energia da moagem ser dissipada em deformações elástica e plástica, que não a de fratura (Parrot, 1986).

A Figura 1 ilustra a distribuição granulométrica para as folhas e caules secos e moídos. O conhecimento da distribuição granulométrica é relativamente útil na indicação da tamisação como o procedimento prévio aos processos, onde a homogeneidade do tamanho de partículas pode interferir. Embora a distribuição seja bimodal, as diferentes partes do material vegetal apresentaram um perfil muito semelhante de distribuição granulométrica, o que faz com que a distribuição da mistura das diferentes partes seja muito previsível.

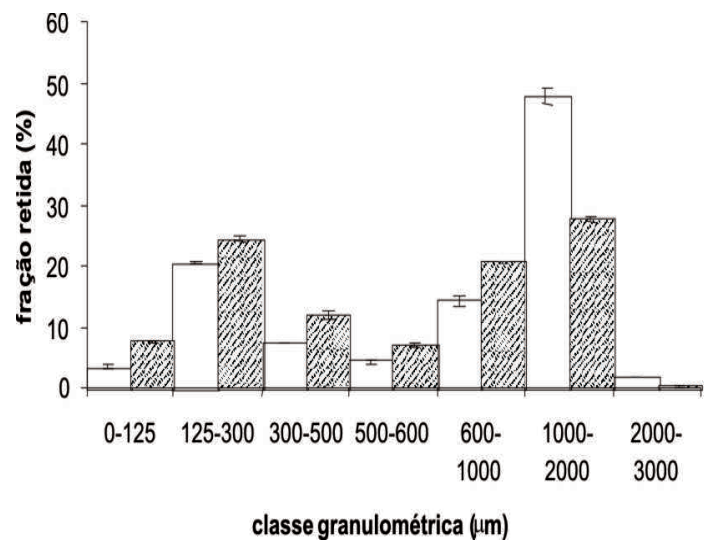

DFOLHAS RCAULES

Figura 1. Distribuição granulométrica de caules e folhas secos e moídos de Ipomoea pes-caprae.

Os resultados das determinações das cinzas totais, insolúveis em ácido clorídrico e sulfatadas estão descritos na Tabela 3.

Tabela 3. Determinação de cinzas (média \pm desvio padrão, desvio padrão relativo\%) das partes vegetais secas e moídas de Ipomoea pes-caprae.

\begin{tabular}{cccc}
\hline $\begin{array}{c}\text { Parte da } \\
\text { planta }\end{array}$ & \multicolumn{1}{c}{ Cinzas totais } & $\begin{array}{c}\text { Cinzas insolúveis } \\
\text { em HCl }\end{array}$ & Cinzas sulfatadas \\
\hline Folha & $12,51 \pm 0,82(6,55)$ & $12,60 \pm 0,44(3,53)$ & $12,60 \pm 0,44(3,53)$ \\
Caule & $7,99 \pm 0,89(11,11)$ & $6,85 \pm 0,25(3,64)$ & $6,85 \pm 0,25(3,64)$ \\
Inteira & $9,84 \pm 0,13(1,35)$ & $8,48 \pm 0,65(7,62)$ & $8,48 \pm 0,65(7,62)$ \\
\hline
\end{tabular}

A determinação do teor de cinzas permite a verificação de impurezas inorgânicas não voláteis que podem estar presentes como contaminantes (Farias, 2003). Os resultados indicam que a presença de materiais inorgânicos na planta inteira reconstituída é proporcional ao teor dos caules, que está presente em maior quantidade na mistura. As cinzas insolúveis em ácido clorídrico permitem a verificação de contaminantes como resíduo de terra ou areia, geralmente observada em raízes (Farias, 2003). Assim podem-se justificar os altos valores de impurezas pela origem da Ipomoea pes-caprae, sendo uma planta rasteira e encontrada extensivamente sobre as dunas das praias.

A cromatografia em camada delgada permite analisar a composição e a pureza do material estudado, auxiliando na identificação de problemas como a adulteração ou falsa identidade da espécie vegetal de interesse. Observou-se que nos cromatogramas para as soluções-amostra de Ipomoea pes-caprae, há indicação da presença de isoquercitrina (Tabela 4), nas folhas e planta inteira, não sendo evidente nos caules, para a concentração aplicada. Além disso, não foi possível visualizar a presença de quercetina em todas as amostras, muito provavelmente devido à sua concentração insignificante no extrato, já que se sabe que a mesma já foi isolada da espécie (Krogh et al., 1999).

Observou-se também a presença de outros compostos sinalizados pelas manchas com valores de $\mathrm{R}_{\mathrm{f}}$ presentes de forma semelhante nas folhas, caule e na planta inteira, com maior intensidade de coloração nas folhas, seguida da planta inteira e caules.

Tabela 4. Resultados da cromatografia em camada delgada para as soluções hidroetanólicas de folhas, caules, planta inteira, quercetina e isoquercitrina após eluição em sistema ácido fórmico:ácido acético:água:acetato de etila (11:11:27:100 v/v) reveladas com solução metanólica de difenilboriloxi-etilamina a $1 \%(\mathrm{~m} / \mathrm{v})$, fixadas com solução etanólica de polietilenoglicol 4000 a $0,5 \%(\mathrm{~m} / \mathrm{v})$, e observadas sob luz UV em $356 \mathrm{~nm}$

\begin{tabular}{lcc}
\hline Manchas & $\mathrm{R}_{\mathrm{f}}$ & Coloração \\
\hline 1 & 0,59 & Azulada \\
$2^{*}$ & 0,76 & Alaranjada \\
3 & 0,85 & Esverdeada \\
$4^{*}$ & 0,87 & Alaranjada \\
quercetina & 0,97 & Alaranjada \\
Isoquercitrina & 0,71 & Alaranjada \\
\hline
\end{tabular}

*para a concentração aplicada, não foi visualizada a mancha na amostra referente aos caules.

Os resultados do teor de extrativos solúveis em água e teor de flavonoides totais estão descritos na Tabela 5. O teor de extrativos indica a presença de compostos hidrossolúveis presentes no material vegetal, como aminoácidos, açúcares, heterosídeos flavonoídicos e mucilagens (Costa, 2002). Verificou-se no presente 
estudo que nas folhas há maior quantidade de substâncias hidrossolúveis.

Tabela 5. Resultados (média \pm desvio padrão, desvio padrão relativo\%) do teor de extrativos (TE) solúveis em água e teor de flavonoides totais (TFT) das partes vegetais secas e moídas de Ipomoea pes caprae.

\begin{tabular}{ccc}
\hline Parte da planta & TE $(\%, \mathrm{~m} / \mathrm{m})$ & TFT $(\mathrm{g} \%)$ \\
\hline Folha & $44,51 \pm 7,69(17,27)$ & $2,409 \pm 0,2114(8,77)$ \\
Caule & $29,22 \pm 4,26(14,57)$ & $0,365 \pm 0,0057(1,58)$ \\
Inteira & $31,26 \pm 2,60(8,34)$ & $0,814 \pm 0,0110(1,36)$ \\
\hline
\end{tabular}

Para o teor de flavonoides, observaramse diferenças quantitativas (Tabela 5), comumente encontradas entre as diferentes partes de uma mesma espécie vegetal (Hostettmann et al., 2003). Nas folhas, o teor de flavonóides totais representa cerca de quatro vezes o teor encontrado nos caules. Em relação à planta inteira, espera-se que o teor de flavonoides seja diluído devido à maior proporção de caules, os quais apresentaram valores bastantes reduzidos desta classe de substâncias.

Nas folhas verificou-se que o teor de extrativos é diretamente proporcional à concentração de flavonóides (Figura 2), sendo a correlação estatisticamente significativa $(\mathrm{r}=0,9962, \alpha=0,05)$.

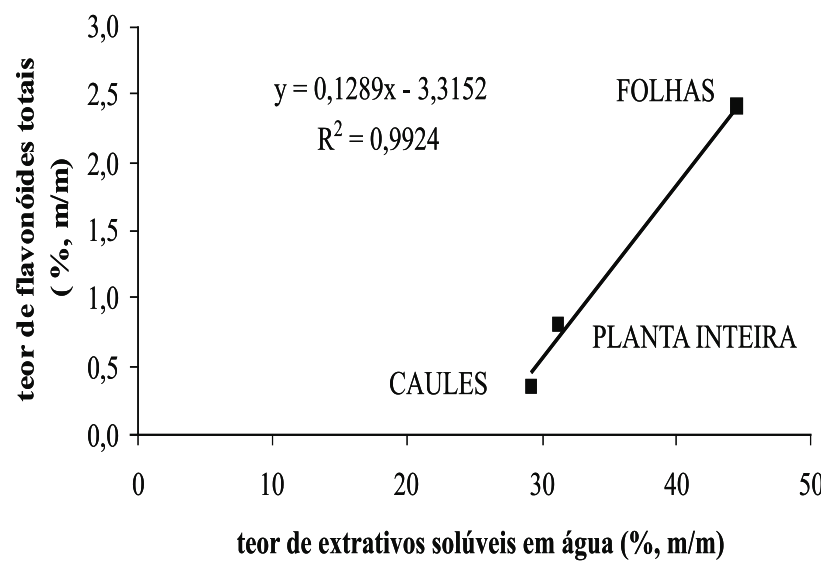

Figura 2. Correlação entre o teor de extrativos solúveis em água e o teor de flavonoides totais para as diferentes partes vegetais da Ipomoea pes-caprae.

Os resultados da análise química qualitativa, obtidos a partir da CCD para polifenólicos, permitem concluir que folhas, caules, bem como a planta inteira possuem composição semelhante, porém indicam que nas folhas são quantitativamente superiores. Quanto aos flavonoides totais, a presença é abundante nas folhas. Cabe ressaltar que embora sejam diferentes quanto à composição, os dados são insuficientes para selecionar a parte da planta a ser utilizada, pois outros critérios devem ser ponderados como a viabilidade econômica e sustentável para a sua utilização como matéria-prima vegetal, tendo em vista os rendimentos de matéria seca. $\mathrm{O}$ teor de flavonoides foi diretamente proporcional ao teor de extrativos solúveis em água entre as folhas, caule e planta inteira, podendo ser utilizado como auxiliar útil na identificação de adulterantes nos lotes de planta inteira, ou da proporção entre as diferentes partes.

\section{AGRADECIMENTOS}

A realização deste trabalho recebeu suporte financeiro e bolsa estudantil do Artigo 170 da UNIVALI/ Governo Estadual. VCF agradece ao CNPq pelo apoio financeiro.

\section{REFERÊNCIAS}

Allen LV, Popovich NG, Ansel HC 2007. Formas Farmacêuticas e Sistemas de Liberação de Fármacos. Porto Alegre: Artmed.

Brasil. Ministério da Saúde. Agência Nacional de Vigilância Sanitária. Resolução de Diretoria Colegiada ${ }^{\circ} 48$ de 16 de março de 2004. Dispõe sobre o registro de medicamentos fitoterápicos. D.O.U., 18. mar.2004.

Bundesvereinigung Deutscher Apothekerverbände (Hrsg.). Deutscher Arzneimittel - Codex. 1986. Frankfurt: Govi; Stuttgart: Deutscher Apotheker, 1986. v. 1: Codex - Probe 4,9 .

Calixto JB 2005. Twenty-five Years of Research on Medicinal plants in Latin América: A personal view. $J$ Ethnopharmacol 100: 131-134.

Costa AF 2002. Farmacognosia. Lisboa: Calouste Gulbenkian.

Cragg GM, Newman DJ 2007. Biodiversidade: Um componente essencial na descoberta de novos fármacos. In: Yunes RA, Cechinel-Filho V (org.) 2007. Química de produtos naturais, novos fármacos e a moderna farmacognosia. 1.ed. Itajaí: UNIVALI.De Souza MM, Madeira A, Berti C, Krogh R, Yunes RA, Cechinel-Filho V 2000. Antinociceptive properties of the methanolic extract obtained from Ipomoea pes-caprae (L) R. Br. J Ethnopharmacol 69: 85-90.

Emendorfer F, Bellato F, Noldin VF, Niero R, Cechinel-Filho V, Cardoza AM 2005. Evaluation of the relaxant action of some Brazilian medicinal plants in isolated guinea-pig ileum and rat duodenum. J Pharm Pharm Sci 8: 63-68.

Farias MR 2003. Avaliação da qualidade de matérias-primas vegetais. In: Simões CMO, Schenkel EP, Gosmann G, Mello JCP, Mentz LA, Petrovick PR (org.) Farmacognosia: da planta ao medicamento. 5.ed. Porto Alegre: UFRGS, Florianópolis: UFSC.

Farmacopéia Brasileira 1988. 4. ed., São Paulo: Atheneu.

Farmacopéia Brasileira 2001. 4. ed., São Paulo: Atheneu.

Hostettmann K, Queiroz EF, Vieira PC 2003. Princípios ativos de plantas superiores. São Carlos: Edufscar.

Krogh R, Berti C, Madeira AO, Souza MM, Cechinel-Filho V, Delle-Monache F, Yunes RA 1999. Isolation and identification of compounds with antinociceptive action 
from Ipomoea pes-caprae (L). R. Br. Pharmazie 54: 464466.

Parrott EL 1986. Milling. In: Lachmann L, Lieberman HA, Kanig JL (Eds.) The Theory and Practice of Industrial Pharmacy. Philadelphia: Lea Febiger, p. 21.

Pongprayoon U, Baeckstrom P, Jacobsson U, Lindstrom M, Bohlin L 1992. Antispasmodic activity of beta-damascenone and E-phytol isolated from Ipomoea pes-caprae. Planta Med 58: 19-21.

Pongprayoon U, Baeckstrom P, Jacobsson U, Lindstrom M, Bohlin L 1991a. Compounds inhibiting prostaglandin synthesis isolated from Ipomoea pes-caprae. Planta Med 57: $515-518$.

Pongprayoon U, Bohlin L, Wasuwat S 1991b. Neutralization of toxic effects of different crude jellyfish venoms by an extract of Ipomoea pes-caprae (L). R. Br. $J$ Ethnopharmacol 35: 65-69.

Pongprayoon U, Bohlin L, Sandberg F, Wasuwat S 1989. Inhibitory effect of extract of Ipomoea pes-caprae on guinea-pig ileal smooth muscle. Acta Pharm Nordica 1: 41-44.

Sonaglio D, González Ortega G, Petrovick PR, Bassani VL 2003. Desenvolvimento tecnológico e produção de fitoterápicos. In: Simões CMO, Schenkel EP, Gosmann G, Mello JCP, Mentz LA, Petrovick PR (org.) Farmacognosia: da planta ao medicamento. 5.ed. Porto Alegre: UFRGS, Florianópolis: UFSC.

WasuwatS 1970.Extract of Ipomoeapes-caprae(Convolvulaceae) antagonistic to histamine and jelly-fish poison. Nature 225: 758-759. 